International Journal of Instruction

e-ISSN: 1308-1470 • www.e-iji.net
July $2018 \bullet$ Vol.11, No.3

p-ISSN: 1694-609X

pp. 491-510

Received: 09/12/2017

Revision: 24/04/2018

Accepted: 30/04/2018

\title{
EFL Teacher's Pedagogical Knowledge Base as a Predictor of Teacher's Reflectivity: Comparing Different Components and Perceptions
}

\author{
Masoomeh Estaji \\ Asst. Prof. Allameh Tabataba'i University, Iran, mestaji74@gmail.com \\ Shabnam Dezfoolian \\ Allameh Tabataba'i University, Iran, shabnam.dezfoolian@gmail.com
}

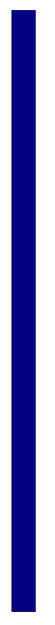

\begin{abstract}
Teacher reflection is a salient activity which can assist teachers in getting a critical view about their effective teaching (Loughran, 2010). Among various factors that influence the teachers' reflection, teacher's Pedagogical Knowledge Base (PKB) can be considered of great significance. The current study sought to investigate the relationship between Iranian EFL teachers' PKB and their reflection. Further, the predictive power of PKB components in relation to teacher reflection was examined. In this mixed methods design study, $108 \mathrm{EFL}$ teachers completed the teacher reflection (Akbari, Behzadpoor, \& Dadvand, 2010) and teacher's Pedagogical Knowledge Base (Akbari \& Dadvand, 2014) questionnaires. In the qualitative phase of this study, 20 male and female EFL teachers with high and low PKB were interviewed to extract their perceptions of reflection and reflective practice. To analyze the data, Pearson Product-moment correlation coefficient was run and the obtained results showed that there was a significant positive relationship between teachers' PKB and reflection. Besides, by running multiple regressions, it was revealed that the teachers' PKB can predict the teacher's reflection significantly.
\end{abstract}

Keywords: reflection, teacher reflection, teacher's knowledge, teacher's Pedagogical Knowledge Base, teacher perception

\section{INTRODUCTION}

In the educational domains, teachers have a significant role in setting up a meaningful learning experience for the students (Davis \& Krajcik, 2005; Fishman, Marx, Best, \& Tal, 2003) and their achievement and failure (Dembo \& Gibson, 1985). In particular, teachers are responsible for creating a friendly and positive learning environment in the classroom, providing a well-designed syllabus and effective materials, and helping students reach their objective, which all lead to effective learning (Xia, 2002). Nonetheless, teachers are not invariably adroit at presenting such meaningful experiences for the students and that teaching is "a complex and highly skilled activity

Citation: Estaji, M., \& Dezfoolian, S. (2018). EFL Teacher's Pedagogical Knowledge Base as a Predictor of Teacher's Reflectivity: Comparing Different Components and Perceptions. International Journal of Instruction, 11(3), 491-510. https://doi.org/10.12973/iji.2018.11334a 
which, above all, requires classroom teachers to exercise judgment in deciding how to act" (Pollard \& Collins, 2005, p. 4). Hence, teacher educators should put the teachers in the center of attention and design teacher training courses to improve teachers' overall practices in the classroom.

As a result of their demanding and complicated profession, teachers encounter time limitation for reflection about their effective teaching and developing expertise in their profession. Richards and Lockhart (1994) introduced the reflective approach as one of the most critical components in the teaching profession; one in which "the teachers and student teachers collect data about teaching, examine their attitudes, beliefs, assumptions, and teaching practices, and use the information obtained as a basis for critical reflection about teaching" (p. 1). Reflective teaching and the practice of reflection have a vital role in the process of effective teaching and learning. Most of the studies on teacher reflection have also demonstrated that reflective teaching can help teachers act effectively (Larrivee, 2000; Richards \& Lockart, 1994; Zeichner \& Liston, 2013). Teachers can reflect and think critically on their challenges in the classroom and choose the best ways to tackle the probable problems. The main types of reflective practice have been explored for the viability and achievement of this practical methodology in making "competent professional" who may have the ability to satisfy the previously stated mission, which is teaching perfectly to their maximum ability (Jay \& Johnson, 2002; Osterman \& Kottkamp, 2004; Pacheco, 2011).

Various factors can impact teachers' reflection and their reflective practice (Akbari, 2007), among which teachers' Pedagogical Knowledge Base (PKB) can be considered as a noteworthy factor. In other words, teachers should have various types of knowledge in order to reflect and act effectively. Teacher's knowledge base is one of the most important factors, which can lead to success of any educational system. The world is changing, therefore; teachers should promote their knowledge and skills and adapt themselves to the new situations. Hence, to keep up with these changes in the economic, social, political, and cultural conditions, teachers need to be trained continuously in order to become more efficient in their teaching. Improving classroom teaching can increase students' learning and this is possible through improving teachers' own knowledge (Hiebert, Gallimore, \& Stigler, 2002; Lampert, 2001).

The problem which may arise is that sometimes teachers lack some specific types of knowledge or they are not up to date with regard to specific knowledge type. Studies have shown that teachers rarely make use of shared knowledge base to improve their practice. It is illustrated that they do not generally locate and translate research-based knowledge into their practice in the classroom (Grimmett \& MacKinnon, 1992; Richardson \& Placier, 2001). For instance, in their students' learning of the curriculum, teachers do not search the studies to help them understand their conceptions and misconceptions, determine their students' learning path, or make alternative teaching practices that are more fruitful in helping their students learn better and master the curriculum (Hiebert, Gallimore, \& Stigler, 2002).

Considering the importance of teacher reflection and reflective teaching and the factors which can play a role in this regard, such as teachers' PKB that is constructed, shared, 
and reconstructed in their content domain by reflecting upon their interactions with students in various education contexts, this study attempted to investigate the relationships between EFL teachers' pedagogical knowledge base and reflection. Furthermore, for an in-depth analysis of the results, this study identified issues reflected by EFL teachers with high and low PKB and analyzed their perceptions of teacher reflection and reflective practice.

\section{LITERATURE REVIEW}

The term reflection has been deciphered in various ways and takes on various meanings and conceptions. The terms of reflection, critical reflection, reflection practice and reflective inquiry have all been utilized conversely to depict a similar idea. All things considered, there is a general agreement in the literature that reflection in teacher education is an extraordinary type of thought (Dogani, 2008; Loughran \& Hamilton, 2016; McNamara, 1990; Schön, 1995; Sparks-Langer \& Colton, 1991). Dewey (1933) contemplated that reflection precedes intelligent action. Reflective thought is profitable for it emancipates us from just impulsive and simply routine action. It empowers us to direct our exercises with foresight and to plan according to ends in view, or reasons for which we are aware...it changes over activity that is only appetitive, blind, and impulsive to intelligent action.

Historically, Dewey (1933) referred to reflective practice as intelligent action and called it, reflective teaching. He defined reflection as the act of active, persistent, and careful consideration of any belief or supposed forms of knowledge in light of the grounds that support it and the consequence to which it leads. Furthermore, he stated that it involved open-mindedness, wholeheartedness, and responsibility. Schön (1983) extended Dewey's idea of reflection with bringing new points of view on reflective practice standards and procedures in classroom instruction. He recognized two sorts of reflections: Reflection-on-action and reflection in action. He asserted that reflection-onaction can happen prior and then afterward a lesson. Educators arrange a lesson and afterward assess the adequacy of the lesson subsequent to directing classroom instruction, while, then again, reflection in action can happen at the same time when instructors teach and monitor continuous performances.

Farrell (1998) asserted that "reflection-in-action is concerned with thinking about what we are doing... reflection-on-action deals with thinking back on what we have done to discover how our knowledge-in-action may have continued to an unexpected action" ( $p$. 12). As Reed, Davis, and Nyabanyaba (2002) stated reflection-in-action refers to the "insights teachers gain in the classroom, while they are at work" while reflection-onaction involves "recalling, explaining, and evaluating after a lesson and includes thinking about the reflections-in-action that were part of the lesson" (p. 257). As for effective teaching, critical reflection is required on teaching ends, methodology, and students' abilities. To this end, it is necessary for the teachers to determine their mastery over the subjects, pedagogical style, and the students' learning styles and apply innovative pedagogical strategies to deal with the classroom problems. As a consequence of their conducting comprehensive reflections to all major aspects in the 
teaching and learning processes, the teacher's knowledge definitely promotes over time in response to the classroom events and problems.

Effective instruction is a dialectic and dynamic process which takes advantage of trial and error process to determine the best way of teaching. In fact, teachers gain pedagogical knowledge from their sociocultural context rather than translating it from the theory into practice (Mullock, 2006). Teacher's Pedagogical Knowledge Base (PKB) refers to the "accumulated knowledge about the act of teaching, including goals, procedures, and strategies that form the basis of what teachers do in classroom" (Mullock, 2006, p. 48). This knowledge can be both explicit and implicit and it shapes the teachers' decisions and actions in the classroom.

Reviewing the literature on teachers' $\mathrm{PKB}$, three dimensions were highlighted for teacher knowledge: Theoretical, practical, and personal dimensions. Theoretical knowledge which is also known as explicit knowledge can be described as a set of assumptions that the teacher can get from the theories. These theoretical rules about teaching can be verbally and explicitly articulated by the teachers using a technical terminology (Woods \& Çakir, 2011). The second knowledge dimension is practical. As it is obvious, theoretical knowledge is grounded in theories but practical knowledge can be gained through experience. Teachers understand and learn practical knowledge by actual practice (Johnson, 2006; Mangubhai, Marland, Dashwood, \& Son, 2004). The third dimension of teacher knowledge is personal knowledge. It means that the process of knowledge formation is personal and prone to subjectivity. As Borg (2001) contends knowledge is a more or less personal construct and belief which is rooted in individuals' subjective interpretations.

Although teachers' PKB is not a recently developed concept, there are not many studies in this domain. Freeman (2002) reviewed research on teacher knowledge and learning in general education and revealed how the field of second and foreign language education from 1990 to 2000 contextualized this research to accommodate the unique needs of language education. He contended that instructors' mental lives ought to be a starting point for analyzing teacher learning. In an investigation of instructor learning, he emphasized learning of content and teaching practice, teachers' thought processes, the role of earlier information, and the part of social and institutional settings ought to be contemplated. Freeman viewed "context of the mind" (p. 10) as imperative in comprehending pre-service instructors' learning since it works as a meeting point for educators' earlier information and convictions, experience, social position, present experience, and collaboration in instructor training programs.

In another investigation, Gatbonton (2008) explored the similarities and differences between novice and experienced teachers' pedagogical thought patterns. She used stimulus recall design to extract the participants' perceptions. The results showed that both novice and experienced teachers were similar in terms of both the number of pedagogical thoughts that the teachers produced and the types of categories. Some of the categories of pedagogical knowledge for both novice and experienced teacher were reported to be language management, procedure check, progress review, and knowledge of students. 
Following Gatbonton's (2008) and Mullock's (2006) studies, Akbari and Tajik (2009) investigated the differences in the pedagogical knowledge base of Iranian experienced and less experienced EFL teachers. Results of their study revealed differences in the number and order of pedagogical thought units with experienced teachers producing an average of five pedagogical thought units in a minute and the novice ones producing 3 thought units. The dominant thought unit for the less experienced teachers was language management and self-reflection was found more significant for the experienced teachers. In a similar study, Akbari and Dadvand (2011) examined the differences in teacher knowledge base of Iranian EFL teachers with different levels of education. The researchers revealed that the pedagogical thoughts differed between these two groups. It was manifested that the teachers' level of education was the determining factor, as teachers with master's degree produced significantly more thought units compared with the ones with bachelor's degree and the main difference was in their affective thought.

All in all, PKB should be placed at the heart of teacher education. Darling-Hammond (1995) has claimed that teacher learning embodies not only learning about theories but also how these theories are put into practice. Teachers need to have the instructional knowledge required to teach, understand the content, know how to design syllabus and develop courses, use effective pedagogical strategies, manage classes, and more significantly be able to assess students to better identify and regulate the instructional goals and needs.

While many researchers have investigated teacher's knowledge and PKB (see e.g., Freeman, 2002; Freeman \& Johnson, 1998; Gatbonton, 2000, 2008; Mullock, 2006; Watzke, 2007), there remains a gap in our understanding of how this knowledge is related to and predicts the teacher's reflection. For this purpose, the present study was conducted to answer the following research questions.

1. Is there any statistically significant relationship between Iranian EFL teachers' pedagogical knowledge base and their reflective ability?

2. Does EFL teacher's pedagogical knowledge base predict his/her reflection? If yes, which components of teacher's pedagogical knowledge base (knowledge of subject matter, knowledge of learners, knowledge of second language teaching, knowledge of second language learning, knowledge of assessment/testing, knowledge of classroom management, knowledge of educational context, knowledge of equity and diversity knowledge of (professional self) are the best predictors of teacher reflection?

3. What are the perceptions of EFL teachers with high and low pedagogical knowledge base regarding teacher reflection?

\section{METHOD}

This study followed a mixed methods design which entailed both quantitative and qualitative phases. In the quantitative phase of this study, a set of questionnaires was distributed among the participants. After the quantitative data analysis, in the qualitative phase of the study, the researcher analyzed the interviewees' responses to identify the teachers' perceptions of reflectivity through content analysis of their response patterns. 


\section{Participants}

The participants of the quantitative part of this study were 108 Iranian EFL teachers, who have been teaching English in various language institutes of Tehran. The participants of this study were $76(70.37 \%)$ female and $32(29.62 \%)$ male EFL teachers, who were selected through convenience sampling. Convenience sampling is a kind of selection method in which the participants who are easy to access and available are included in the study (Dörnyei, 2007). The participants of the qualitative part of the study were 20 male and female EFL teachers who were also selected using density sampling (Patton, 2014). They were 14 female and six male teachers who had different ranges of teaching experience. The age range of the participants was 22 to 34 years old

\section{Instrumentation}

In this study, a set of questionnaires were used to measure the teacher's reflective ability, and pedagogical knowledge base. Furthermore, a set of interview questions were used to explore teachers' perceptions of reflective teaching in depth. The description of the questionnaires, encompassing their developers, numbers of items and constructs as well as the reliability and validity of each, and teachers' semi-structured interview are provided in detail in the following sections.

\section{Teacher Reflection Questionnaire}

In this study, in order to assess teacher reflection, the "reflective teaching instrument" developed by Akbari, Behzadpoor, and Dadvand (2010) was used. This instrument contains 29 items, which assesses teacher's reflection through a 5-point Likert scale (Never, rarely, sometimes, often, and always). To describe the questionnaire in detail, this instrument previously had 42 items on six different sub-scales: Practical, metacognitive, cognitive, critical, affective and moral including seven items for each sub-scale but piloting the questionnaire with 300 ESL teachers, the items were reduced to 29 items. Through eliminating the moral sub-scale, five factors remained in the final version of the questionnaire with the reliability indices measured as: 1. Practical reflection ( $r=0.57)$, 2. Cognitive reflection $(r=0.68), 3$. Affective reflection $(r=0.59), 4$. Metacognitive reflection ( $r=0.52)$, and 5. Critical reflection $(r=0.65)$.

\section{Teachers' Sense of Pedagogical Knowledge Base Questionnaire}

In the current study, to assess teachers' pedagogical knowledge base, a questionnaire which was recently developed and validated by Dadvand (2013) was utilized. Dadvand (2013) developed this questionnaire to estimate the knowledge of EFL teachers. Teachers' pedagogical knowledge base contains 50 items. Each item is assessed through a 5-point Likert scale which ranges from 1-nothing, 2- very little, 3- some influence, 4quite a bit, and 5- a great deal.

Teacher's pedagogical knowledge base questionnaire has 9 components/constructs which include: (a) knowledge of subject matter, (b) knowledge of learners, (c) knowledge of second language teaching, (d) knowledge of second language learning, (e) knowledge of assessment/testing, (f) knowledge of classroom management assessed, (g) knowledge of educational context, (h) knowledge of equity and diversity, and finally (i) knowledge of (professional) self. The reliability of this questionnaire is reported to be .94 and it enjoys construct validity (Dadvand, 2013). 


\section{Semi-Structured Interview Regarding Teacher Reflection}

In the qualitative phase of this study, to explore the teacher's perceptions regarding teacher reflection and reflective practice in depth, which is the study's important variable, after gathering participants' perceptions using the mentioned questionnaires, a semi-structured interview was run with 20 teachers, who scored high and low in pedagogical knowledge base. To this end, the top most and bottom most quartiles were considered based on the participants' mean score in the pedagogical knowledge base questionnaire. The researcher used a set of 9 questions, which were adapted from Akbari et al. (2010). They reported that these interview questions were a valid and reliable measure to assess EFL teachers' perceptions of reflection and reflective teaching.

\section{Data Collection Procedure}

To collect the data, at the outset of the study, the questionnaires (teacher's reflection instrument and teacher's pedagogical knowledge base) were pilot tested on $35 \mathrm{EFL}$ teachers with similar characterises as the participants of the main phase of the study and their reliability indices were measured. Cronbach's alpha was run and the reliability indices for the teacher reflection and PKB questionnaires were found .90 and .96 respectively. In the quantitative phase of the study, the piloted questionnaires and a demographic information questionnaire were used. The questionnaires were distributed both online and in hard copies. The questionnaires were put online through Google forms and then the questionnaire link was emailed to the participants. Furthermore, some of the questionnaires were handed in hard copies, mainly for those who had no access to internet or preferred to fill out the questionnaire in this way. The participants were given enough information about the questionnaires' topics and how to fill them out. After data collection, the data were fed into Statistical Packages for Social Sciences (SPSS) for detail analysis. Moreover, 20 teachers were selected to be interviewed. To explore the selected teachers' perceptions regarding their reflective beliefs and practices, those teachers whose scores in the pedagogical knowledge base questionnaire were one Standard Deviation (SD) above and below the mean were chosen and attended a semi-structured interview. To this end, primarily, the researcher asked the participants for their consents and those who had high and low scores in their pedagogical knowledge base questionnaires took part in this phase. The data then were analyzed content wisely and the answers were categorized and coded. The results of the interview section were reported in frequency and percentage and wherever required tables and figures were presented.

\section{Data Analysis}

After the data collection, the results were fed into SPSS software. To answer the first research question regarding the possible relationships between teachers' pedagogical knowledge base and their reflective ability, a Pearson product moment correlation coefficient was used. As for the second research question, to determine the best predictors of teacher reflection through teacher's pedagogical knowledge base components, a multiple regression was run. To answer the third question of the study and after interviewing the selected participants who had high and low pedagogical knowledge, their answers were gone through content analysis. In particular, the perceptions of teachers were analyzed using frequency count and descriptive statistics. 


\section{FINDINGS}

\section{Results Regarding the First Research Question}

The first research question identified whether there was any statistically significant relationship between teachers' PKB and their reflective ability. To do so, a Pearson correlation was run (Table 3); however, before that descriptive statistics were measured (Tables 1 and 2).

Table 1

Descriptive Statistics Regarding Teacher Pedagogical Knowledge Base

\begin{tabular}{|c|c|c|c|c|c|}
\hline Teacher & $\mathrm{N}$ PKB & Minimum & Maximum & Mean & Std. Deviation \\
\hline 108 & & 103.00 & 249.00 & 200.35 & 27.19 \\
\hline
\end{tabular}

Table 2

Descriptive Statistics Regarding Teacher Reflection

\begin{tabular}{llllll}
\hline Teacher & N PKB & Minimum & Maximum & Mean & Std. Deviation \\
\hline 108 & & 68.00 & 140.00 & 108.78 & 15.94 \\
\hline
\end{tabular}

Table 3

Pearson Correlation, Teacher Reflection and Pedagogical Knowledge Base

\begin{tabular}{lll}
\hline & & Teacher Reflection \\
\hline \multirow{3}{*}{ Pedagogical Knowledge-bas } & Pearson Correlation & $.48^{* *}$ \\
\cline { 2 - 3 } & Sig. (2-tailed) & .00 \\
\cline { 2 - 3 } & $\mathrm{N}$ & 108 \\
\hline
\end{tabular}

**. Correlation is significant at the 0.01 level (2-tailed).

The results indicated a moderate significant relationship between the two variables, $r$ $(108)=.48, \mathrm{P}<.05$. Thus, the first null hypothesis as there was not any significant correlation between EFL teachers' PKB and their reflective ability was rejected. Scatter Plot (Figure 1) probes the assumptions of linearity and homoscedasticity.

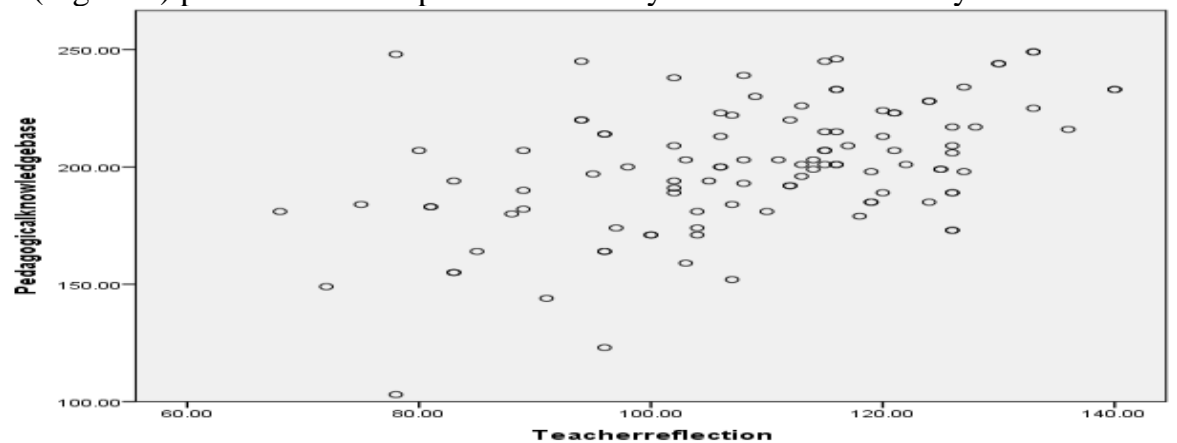

Figure 1

Scatter Plot illustrating Teachers' Pedagogical Knowledge Base (PKB) and Teacher Reflection (TR) 
According to the scatterplot 1 , the spread of dots did not show a rise and fall pattern. Thus, it can be concluded that the relationship between the two variables was linear. The spread of dots did not show a funnel shape either, i.e., narrow at one end and wide at the other end. Thus, the homoscedasticity - homogeneity of variances - assumption was also met.

\section{Results Regarding the Second Research Question}

The second research question investigated whether teachers' PKB and its components (knowledge of subject matter, knowledge of learners, knowledge of second language teaching, knowledge of second language learning, knowledge of assessment/testing, knowledge of classroom management, knowledge of educational context, knowledge of equity and diversity knowledge of (professional) self) can predict teacher reflection. For this end, a multiple regression was run to predict teachers' reflection by using their PKB and its components. The results are illustrated in Table 4.

Table 4

Multiple Regression Analysis

\begin{tabular}{|c|c|c|c|}
\hline \multicolumn{2}{|c|}{ Model R } & \multicolumn{2}{|c|}{ R Square Adjusted R Square Std. Error of the Estimate Durbin-Watson } \\
\hline 1 & $.68^{\mathrm{a}} .47$ & .42 & \\
\hline 2 & $.68^{\mathrm{b}} .47$ & .42 & \\
\hline 3 & $.68^{\mathrm{c}} .46$ & .43 & \\
\hline 4 & $.68^{\mathrm{d}} .46$ & .43 & \\
\hline 5 & $.67^{\mathrm{e}} .45$ & .43 & 1.75 \\
\hline
\end{tabular}

a. Predictors: (Constant), KPS, KL, KCM, KAT, KSM, KED, KEC, KSLT, KSLL

b. Predictors: (Constant), KPS, KL, KCM, KAT, KSM, KEC, KSLT, KSLL

c. Predictors: (Constant), KPS, KL, KCM, KAT, KEC, KSLT, KSLL

d. Predictors: (Constant), KPS, KL, KCM, KAT, KSLT, KSLL

e. Predictors: (Constant), KPS, KL, KAT, KSLT, KSLL

f. Dependent Variable: Teacher reflection

Note. KPS = Knowledge of Professional Self $\quad \mathrm{K} \mid \mathrm{ED}=$ Knowledge of Equity and Diversity

$\mathrm{KL}=$ Knowledge of Learners

$\mathrm{KCM}=$ Knowledge of Classroom Management KSLT $=$ Knowledge of Second Language Teaching

$\mathrm{KAT}=$ Knowledge of Assessment/Testing $\quad \mathrm{KSLL}=$ Knowledge of Second Language Learning

$\mathrm{KSM}=$ Knowledge of Subject Matter

The results (Table 4) indicated that the components of PKB predicted $47 \%$ of teacher reflection $\left(\mathrm{R}=.68, \mathrm{R}^{2}=.47\right)$. On the second, third, and fourth steps, the non-significant components were excluded reducing the predictive power to 45 percent $\left(R=.67, R^{2}=.45\right)$. In this model, it was revealed that the knowledge of (professional) self, knowledge of learners, knowledge of assessment/testing, knowledge of second language teaching, and knowledge of second language learning sub-component of teachers' PKB are the best predictors of teachers' reflection. The Durbin-Watson index of 1.75 indicated that the error residuals were uncorrelated. Moreover, to find out which components of PKB significantly predicted teacher reflection, an ANOVA was run. The results are presented in Table 5.

Table 5

ANOVA Results Regarding the Components of PKB

\begin{tabular}{|c|c|c|c|c|c|c|}
\hline \multicolumn{2}{|c|}{ Model } & Sum of Squares & $\mathrm{df}$ & Mean Square & $\mathrm{F}$ & Sig. \\
\hline \multirow{3}{*}{1} & Regression & 12791.64 & 9 & 1421.29 & 9.67 & $.00^{\mathrm{b}}$ \\
\hline & Residual & 14404.46 & 98 & 146.98 & & \\
\hline & Total & 27196.10 & 107 & & & \\
\hline
\end{tabular}




\begin{tabular}{|c|c|c|c|c|c|c|}
\hline \multirow{3}{*}{2} & Regression & 12771.34 & 8 & 1596.41 & 10.95 & $.00^{\mathrm{c}}$ \\
\hline & Residual & 14424.75 & 99 & 145.70 & & \\
\hline & Total & 27196.10 & 107 & & & \\
\hline \multirow{3}{*}{3} & Regression & 12751.22 & 7 & 1821.60 & 12.61 & $.00^{\mathrm{d}}$ \\
\hline & Residual & 14444.87 & 100 & 144.44 & & \\
\hline & Total & 27196.10 & 107 & & & \\
\hline \multirow{3}{*}{4} & Regression & 12650.56 & 6 & 2108.42 & 14.64 & $.00^{\mathrm{e}}$ \\
\hline & Residual & 14545.53 & 101 & 144.01 & & \\
\hline & Total & 27196.10 & 107 & & & \\
\hline \multirow{3}{*}{5} & Regression & 12447.01 & 5 & 2489.40 & 17.21 & $.00^{\mathrm{f}}$ \\
\hline & Residual & 14749.09 & 102 & 144.59 & & \\
\hline & Total & 27196.10 & 107 & & & \\
\hline
\end{tabular}

a. Dependent Variable: Teacher reflection

b. Predictors: (Constant), KPS, KL, KCM, KAT, KSM, KED, KEC, KSLT, KSLL

c. Predictors: (Constant), KPS, KL, KCM, KAT, KSM, KEC, KSLT, KSLL

d. Predictors: (Constant), KPS, KL, KCM, KAT, KEC, KSLT, KSLL

e. Predictors: (Constant), KPS, KL, KCM, KAT, KSLT, KSLL

f. Predictors: (Constant), KPS, KL, KAT, KSLT, KSLL

Note. KPS = Knowledge of Professional Self $\mathrm{K} \mid \mathrm{ED}=$ Knowledge of Equity and Diversity

$\mathrm{KL}=$ Knowledge of Learners

$\mathrm{K} \mid \mathrm{ED}=$ Knowledge of Equity and Diversity
$\mathrm{KEC}=$ Knowledge of Educational Context

$\mathrm{KCM}=$ Knowledge of Classroom Management $\quad$ KSLT $=$ Knowledge of Second Language Teaching

KAT $=$ Knowledge of Assessment/Testing $\quad$ KSLL $=$ Knowledge of Second Language Learning

$\mathrm{KSM}=$ Knowledge of Subject Matter

The results of the ANOVA test (Table 5) indicated that the components of PKB significantly predicted teacher reflection, $\mathrm{F}(5,102)=17.21, \mathrm{P}<.05$. The $\mathrm{P}$ value is less than .05 , which can be interpreted as indicating a statistically significant interaction between teachers' PKB and their reflection. The results in Figure 2 indicated that the assumptions of linearity and homoscedasticity were met.

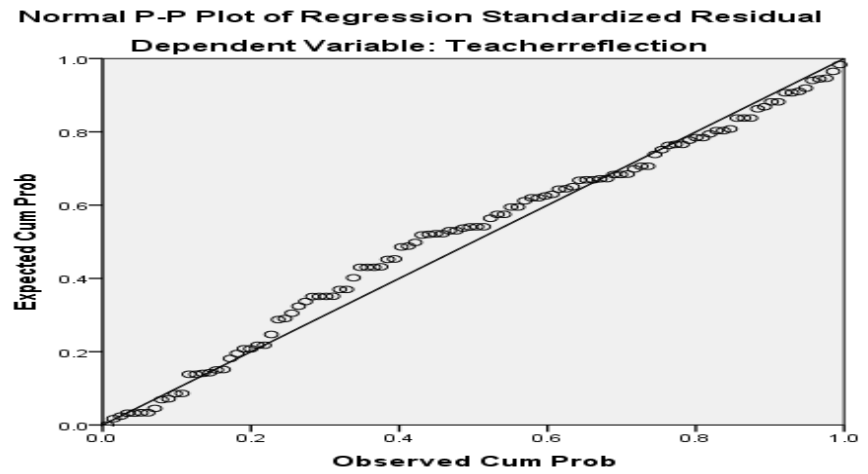

Figure 2

Normal P_P Plot Testing Assumption of Normality of teacher reflection scores

As can be seen in Figure 2, the spread of dots did not form a curve shape. Thus, it can be concluded that the relationship between the two variables was linear. They did not show a funnel shape either, i.e., narrow at one end and wide at the other end. Thus, the homoscedasticity - homogeneity of variances - assumption was also met.

International Journal of Instruction, July $2018 \bullet$ Vol.11, No.3 


\section{Discussion for the Quantitative Results}

The aim of the current study was to investigate the role of EFL teachers' pedagogical knowledge base in predicting their reflective teaching. The results of the first quantitative research question of the study, investigating the relationship between EFL teachers' pedagogical knowledge base and their reflection, revealed that there was a positive and significant relationship between these two factors.

Teacher's pedagogical knowledge base has much in common with cognitive reflection. Cognitive reflection is related to thinking processes and activities that teachers do. The teacher's pedagogical knowledge is explicated in terms of the tripartite domains of teacher knowledge base (Freeman \& Johnson, 1998): Teacher as a learner of teaching, knowledge of sociocultural context, and pedagogical approaches. Here, an important premise is that a teacher's pedagogical knowledge cannot be isolated from the teacher as a unique person and his knowledge of the sociocultural contexts of teaching (Freeman \& Johnson, 1998). This finding seems to be consistent with that of Park and Oliver's (2008) finding which showed the development of teachers' Pedagogical Content Knowledge through reflection-in-action and reflection-on-action.

This finding also corroborates the idea of Schön (1987), who believed that teacher reflection is an essential factor for constructing teachers' knowledge bases and the understanding of professional practices. Borg (2003) also determines various factors including teacher's PKB which are effective in forming the teacher's cognition. Teacher reflection also plays a central role in determining the teacher cognition. Shulman (1987) further contends that all pedagogical processes are underpinned by a knowledge base that supports the making of all pedagogical choices.

It is also encouraging to compare this finding with that found by Akbari and Tajik (2009), analyzing the pedagogical knowledge base of Iranian experienced and less experienced EFL teachers. Based on the results, self-reflection was found the dominant thought category for the experienced teachers. Similarly in Gatbonton's $(2000,2008)$, Karimi's (2011), and Mullock's (2006) studies, among the pedagogical thought categories, self-reflection formed the dominant category of Standard Licensed teachers. Hence, it can be concluded that reflective teachers are the ones who take advantage of their pedagogical knowledge base. It can be also inferred that this knowledge base can play a significant role in making them reflective, and that there is a reciprocal relationship between teacher reflection and his/her PKB.

The second research question examined if the teacher's PKB and its components could predict teacher reflectivity. The results showed that knowledge of professional self, knowledge of learners, knowledge of assessment/testing, knowledge of second language teaching, and knowledge of second language learning sub-component of teachers' PKB were the best predictors of teachers' reflection. This accords with Richards' (1998) and Tsui's (2003) studies which have found the various dimensions of knowledge base a suitable reference to investigate the core knowledge base of L2 teachers. In other words, PKB and its components support teacher reflection and help teachers become more aware of their pedagogical processes. A recent study by Karimi and Norouzi (2017) also 
reported significant differences in novice teachers' construction and classification of pedagogical thought units through mentoring. Consequently, PKB should be emphasized in teacher education programs and all professional activities set for the teachers.

\section{DISCUSSION}

The qualitative question of the study concentrated on the perceptions of EFL teachers with high and low pedagogical knowledge base regarding teacher reflection. To this end, the interviews were analyzed and reported in frequency and percentage. The interview results and the themes extracted from the participants' responses are presented in this section.

With regard to being a reflective teacher, teachers with high PKB (HPKB, 75\%) found themselves more reflective than their low PKB counterparts (LPKB, 62.5\%). More than a half of both high and low PKB teachers defined reflective teaching as "thinking about your teaching and evaluating your pedagogical style and practices in and out of the classroom". They also referred to "reflection by focusing on the problems and possible solutions we can have for our students' learning". To low PKB teachers (40\%), teacher reflection meant "learning by practicing to improve effective teaching. The following excerpts represent the way high and low PKB participants defined reflective teaching.

Teacher 5/HPKB: Reflective teaching means teachers think about their teaching, experience and how their teaching or behaviour in or out of classroom may affect their students.

Teacher 12/LPKB: For me, reflective teaching is looking back, thinking about, and evaluating what I have done in the classroom.

As for the characteristics of a reflective teacher, a total of $41.5 \%$ of HPKB teachers attributed some features like "responsibility, credibility, accountability, openness to criticism" to reflective teachers; whereas LPKB teachers believed that reflective teachers are those who are mindful, accurate, businesslike, and obligor. The following table (Tables 6) classifies the characteristics of reflective teachers as mentioned by the participants with high and low PKB.

Table 6

High and Low PKB teachers' perception of the characteristics of a reflective teacher

\begin{tabular}{lcc}
\hline HPKB & Frequency & Percentage \\
\hline Being curious and paying attention to the details & 2 & $16.5 \%$ \\
\hline Being responsible, creative, mindful, patient, hardworking & 4 & $33 \%$ \\
\hline Responsibility, credibility, accountability, openness to criticism & 5 & $41.5 \%$ \\
\hline Having diary and being up to date by reading articles & 1 & $8 \%$ \\
\hline LPKB & & \\
\hline Being curious and paying attention to the details & 1 & $14 \%$ \\
\hline Being mindful, accurate, businesslike, and obligor & 2 & $28.5 \%$ \\
\hline Being responsible, creative, mindful, patient, hardworking & 1 & $14 \%$ \\
\hline Having criteria for self-assessment & 1 & $14 \%$ \\
\hline Using lesson plans & 1 & $14 \%$ \\
\hline Having diary and being up to date by reading articles & 1 & $14 \%$ \\
\hline
\end{tabular}


As can be seen, teachers with high PKB have rather better perceptions of the characteristics of a reflective teacher. This finding is in line with the findings of Collier (1999) and Korthagen and Wubbels (1995) who contended that reflective teachers are the ones who are curious, creative, accountable, and hard working.

Teachers' answers to what constitutes reflective teaching were: paying attention to the learners' needs and getting feedback from them (30\%), and assessing the performance of both teacher and students (50\%). This finding concurs with the findings of Brookfield (1995) and Richards and Lockhart (1994) who stated that reflective teaching is thinking about the teaching procedure and trying to improve it. Half of the participants $(54 \%)$ with low PKB and the vast majority of the participants (80\%) with High PKB stated that doing cooperative activities, problem solving practices, program assessment, content of teaching, method of presenting, and classroom management make up the contents of reflection. What follows are sample remarks of teacher participants with high PKB on what constitutes the content of reflective teaching.

Teacher 8/HPKB: Teachers should reflect on and pay attention to the process of teaching, thinking about classes, learners' needs and lacks, and issues related to class teaching.

Teacher 2/HPKB: In my opinion, teacher's behavior to the students, the content of her teaching, her method, her rules of the classes, her classroom management and so on are so significant.

The teachers in high PKB group also stated that affective issues and things related to culture, motivation, and clear methods of instruction are missing from research on reflection; however, teachers in low PKB group mostly had no idea regarding the issues as they were not much familiar with the concept of reflection and reflective teaching.

As for the ways to implement reflective teaching practices in the classroom, using portfolios, observations, and talking to other colleagues were mentioned by HPKB teachers and this agrees with what Akbari et al. (2010) stated about the techniques used to implement reflective teaching principles in the classroom. On the other hand, LPKB teachers referred to items like reviewing literature, lesson plans, considering student needs, and etc. which are somehow different from viewpoints of their high PKB counterparts. It can be implied that they might have less information about the application of reflective teaching practices in their own classrooms. The following samples represent the participants' perspectives in this regard.

Teacher 5/HPKB: I think making a portfolio or a diary is very helpful; writing down what you think may improve your practice along with the outcomes.

Teacher 12/LPKB: A detailed lesson plan could be used to go through the teaching practice after it has taken place and note how effective the strategies employed were and whether modifications are needed in future practices.

Teachers with HPKB had a better understanding and perceptions regarding the importance of critical reflection, which encompasses the social and cultural issues. Mezirow (1990) elaborately discussed the role of critical reflection and how it leads to transformative learning. Furthermore, Smyth (1989) and Yost, Sentner, and ForlenzaBailey (2000) examined the role and importance of critical reflection in teacher 
education. They contended that employing critical reflection will help improve teachers' performance and their relationship with the students. The following excerpt was taken from a participant with high PKB.

Teacher 9/HPKB: I also believe that social, political, and cultural influences should be considered. Because every learning situation takes place in a specific context with its own integral and indispensable cultural, political, and social factors.

All of the teachers in high PKB group contended that moral aspects of reflection are of great importance as well while $60 \%$ of the teacher in low PKB group claimed so. It can be concluded that the teachers who have high pedagogical knowledge base are more aware of the importance of ethics and moral issues in teaching compared with their low counterparts. Here are some samples of the participants' remarks.

Teacher 2/HPKB: Reflective teaching, in my opinion, is moral by itself, since it seeks to promote performance and help people and students enjoy the most of the class.

Teacher 7/HPKB:I think they are more important than transferring knowledge because without them we would have education without morals and this is really dangerous for the societies.

Teacher 2/LPKB: It is a crucial factor; without considering this our teaching is not successful and effective.

At the end, both high and low PKB teachers emphasized the role of affective factors in teacher reflection. As teaching is a profession which includes teacher-student relationship, this finding is justifiable. Hence, all the teachers in their reflections should pay attention to the learners' emotions; otherwise, their teaching would not be that much effective (Hargreaves, 1998, 2000; Nias, 1996; Zeichner \& Liston, 2013).

Teacher 8/HPKB: The establishment of rapport between the teacher and students is very valuable and sometimes the affective factors play even a more crucial role than the cognitive ones in the students' learning progress. So, it is essential for the teachers to reflect on their affective domain and their relationships with their students in the classroom and consider the quality and quantity of their praise and encouragement.

Teacher 17/LPKB: Affective factors are a part of every human concern and to be a reflective teacher is to consider the learner's whole and individuality.

Overall, the analysis of the teachers' responses showed that the participants with HPKB had more comprehensive ideas about reflective teaching. It is noteworthy to state that most of the teachers in LPKB group were not that familiar with the theoretical backgrounds of reflection and reflective teaching and even the practical aspects of reflective teaching. Therefore, teacher education programs should be established in order to increase the knowledge of teachers on reflective teaching and help them apply the principles of reflective teaching in their classroom in order to improve their pedagogical practices and learners' achievements as well.

\section{CONCLUSION}

This study pursued multiple objectives. The first objective was to examine the probable relationship between teacher's reflection and PKB. Second, the predictive power of EFL 
teachers' PKB regarding reflection was assessed. Finally, teachers with high and low PKB talked about their perceptions with regard to reflective teaching in theory and practice.

Based on the collected data, the findings showed that there was a moderate and significant relationship between EFL teachers' PKB and their reflection. Moreover, teachers' pedagogical knowledge base predicted teacher reflection significantly. Knowledge of professional self, knowledge of learners, knowledge of assessment/testing, knowledge of second language teaching, and knowledge of second language learning sub-component of teachers' PKB were the best predictors of teachers' reflection. The overall results of the qualitative phase (interview findings) manifested that there is a difference between the perceptions of the teachers with high and low PKB. Most of the HPKB teachers were familiar with the concept of reflective teaching and its various types. However, teachers with LPKB had a superficial and average understanding of reflective teaching.

The overall results of the study reflected a significant relationship between teacher reflection and pedagogical knowledge base. Moreover, the study revealed the predictive power of PKB and its components. Therefore, the role of teacher's PKB and reflection and their significance in different areas of teacher education cannot be disregarded. In fact, the findings of this study may render some implications for teacher educators and teacher trainers. Teacher educators can become aware of the significance of teacher's $\mathrm{PKB}$ and its various components, and that each teacher may bring different sorts of knowledge to the education context. They should also pay special attention to the teachers' awareness of PKB and reflection and assist them in their pedagogical development. Teacher evaluators may consider this factor as a criterion in the teacher's evaluations and expectations from the teachers. For instance, EFL teachers with high scores on pedagogical knowledge base may have higher eligibility to teach advanced learners or those teachers can be found more confident and efficacious teachers.

Owing to the relationship between teacher's PKB and reflectivity, it is suggested that teachers promote their pedagogical knowledge base to better reflect on their teaching and teaching methods before, while, and after each session and accomplish the objective of the course. As recommended by the participants in the interview phase, teachers can also take advantage of portfolios, journals, narratives, teacher development groups, and video recordings of their classes to improve their reflective practices. Language teachers can practice reflection by using many useful tools such as teaching diaries, peer observation, students' feedback and audio recording (Fatemipour, 2013). Likewise, the school administrators and supervisors can be effectively instructed to have a more constructive role in improving teachers' reflection by providing them with assistance, support, and guidance.

As with any other study, there were certain limitations during the administration of this study that should be taken into account when considering its results and implications. One main limitation of this study was related to the sampling of the participants. The participants of this study were 100 EFL teachers who have been teaching in Tehran's English language institutes. It would certainly be better if the researcher could include 
more EFL teachers from all over the country, in which case the results could have been easily generalized and confidently employed to a greater number of EFL teachers. The other limitation could be the participants' superficial answers to the teacher reflection and pedagogical knowledge base questionnaires, which might be due to their lack of interest in the subject of research or lack of motivation and time to complete the questionnaires thoroughly with precision. However, adding a qualitative phase to the study (teacher interviews) could somehow control this deficiency.

This study can be replicated using different instruments to measure teacher reflection and PKB. With regard to the participants, the sample of participants in this research encompassed both male and female teachers, working for private institutes in Tehran and holding MA degrees in TEFL. This study can be replicated with larger number of participants who also work in public schools or universities with different degrees and levels of education for the sake of comparison and gaining more generalizable results. Moreover, it is suggested that researchers replicate this study taking into account the teacher's demographic information (experience, age, and gender), student-related factors (students' age, gender, and proficiency level) and teacher student-relationship. Likewise, future research might address teacher's professional development since PKB promotes through such practices mainly when it is supported by teacher reflection.

\section{REFERENCES}

Akbari, R. (2007). Reflections on reflection: A critical appraisal of reflective practices in L2 teacher education. System, 35/2, 192-207.

Akbari, R., Behzadpoor, F., \& Dadvand, B. (2010). Development of English language teaching reflection inventory. System, 38/2, 211-222.

Akbari, R., \& Dadvand, B. (2011). Does formal teacher education make a difference? A comparison of pedagogical thought units of BA versus MA teachers. The Modern Language Journal, 95/1, 44-60. https://doi.org/10.1111/j.1540-4781.2010.01142.x

Akbari, R., \& Dadvand, B. (2014). Pedagogical knowledge base: A conceptual framework for teacher admission. System, 42/1, 12-22.

Akbari, R., \& Tajik, L. (2009). L2 Teachers' pedagogic knowledge base: A comparison between experienced and less experienced practitioners. Australian Journal of Teacher Education, 34/6, 52-73. https://doi.org/10.14221/ajte.2009v34n6.4

Borg, E. A. (2001). Knowledge, information and intellectual property: Implications for marketing relationships. Technovation, 21/8, 515-524.

Borg, S. (2003). Teacher cognition in language teaching: A review of research on what language teachers think, know, believe, and do. Language Teaching, 36/2, 81-109. https://doi.org/10.1017/s0261444803001903

Brookfield, S. (1995). Becoming a critically reflective teacher. San Francisco, CA: Jossey-Bass.

Collier, S. T. (1999). Characteristics of reflective thought during the student teaching experience. Journal of Teacher Education, 50/3, 173-181. 
Dadvand, B. (2013). Examining the pedagogical knowledge base of EFL teachers and its relation to teacher reflection and student achievement (Doctoral dissertation). Department of English Language Teaching, Tarbiat Modares University, Tehran, Iran.

Darling-Hammond, L. (1995). Changing conceptions of teaching and teacher development. Teacher Education Quarterly, 22/4, 9-26.

Davis, E. A., \& Krajcik, J. S. (2005). Designing educative curriculum materials to promote teacher learning. Educational Researcher, 34/3, 3-14.

Dembo, M. H., \& Gibson, S. (1985). Teachers' sense of efficacy: An important factor in school improvement. The Elementary School Journal, 3/1, 173-184.

Dewey, J. (1933). How we think: A restatement of reflective thinking to the educative process. Boston: Heath.

Dogani, K. (2008). Using reflection as a tool for training generalist teachers to teach

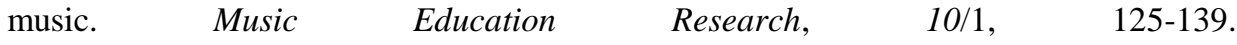
https://doi.org/10.1080/14613800701871595

Dörnyei, Z. (2007). Research methods in applied linguistics: Quantitative, qualitative, and mixed methodologies. Oxford: Oxford University Press.

Farrell, T. B. (1998). Sizing things up: Colloquial reflection as practical wisdom. Argumentation, 12/1, 1-14.

Fatemipour, H. (2013). The efficiency of the tools used for reflective teaching in ESL contexts. Procedia-Social and Behavioral Sciences, 93, 1398-1403.

Fishman, B., Marx, R., Best, S., \& Tal, R. (2003). Linking teacher and student learning to improve professional development in systemic reform. Teaching and Teacher Education, 19/6, 643-658. https://doi.org/10.1016/s0742-051x(03)00059-3

Freeman, D. (2002). The hidden side of the work: Teacher knowledge and learning to teach. Language Teaching, 35/2, 1-13. https://doi.org/10.1017/s0261444801001720

Freeman, D., \& Johnson, K. E. (1998). Reconceptualizing the knowledge-base of language teacher education. TESOL Quarterly, 32/3, 397-417.

Gatbonton, E. (2000). Investigating experienced ESL teachers' pedagogical knowledge. Canadian Modern Language Review, 56/1, 585-616.

Gatbonton, E. (2008). Looking beyond teachers' classroom behaviour: Novice and experienced ESL teachers' pedagogical knowledge. Language Teaching Research, 12/2, 161-182. https://doi.org/10.1177/1362168807086286

Grimmett, P. P., \& MacKinnon, A. M. (1992). Craft Knowledge and the Education of Teachers. Review of Research in Education, 18/1, 385-456.

Hargreaves, A. (1998). The emotional practice of teaching. Teaching and Teacher Education, 14/8, 835-854. https://doi.org/10.1016/s0742-051x(98)00025-0

Hargreaves, A. (2000). Mixed emotions: Teachers' perceptions of their interactions with students. Teaching and Teacher Education, 16/8, 811-826. 
Hiebert, J., Gallimore, R., \& Stigler, J. W. (2002). A knowledge base for the teaching profession: What would it look like and how can we get one? Educational Researcher, $31 / 5,3-15$

Jay, J. K., \& Johnson, K. L. (2002).Capturing complexity: A typology of reflective practice for teacher education. Teaching and Teacher Education, 18/1, 73-85.

Johnson, K. E. (2006). The sociocultural turn and its challenges for second language teacher education. TESOL Quarterly, 40/1, 235-257. https://doi.org/10.2307/40264518

Karimi, M. N. (2011), Variations in EFL teachers' pedagogical knowledge base as a function of their teaching license status. Journal of Teaching Language Skills, 63/3, 83114.

Karimi, M. N., \& Norouzi, M. (2017). Scaffolding teacher cognition: Changes in novice L2 teachers' pedagogical knowledge base through expert mentoring initiatives. System, 65. 38-48. https://doi.org/10.1016/j.system.2016.12.015

Korthagen, F. A., \& Wubbels, T. (1995). Characteristics of reflective practitioners: Towards an operationalization of the concept of reflection. Teachers and Teaching, 1/1, 51-72.

Lampert, M. (2001). Teaching problems and the problems of teaching. New Haven, CT: Yale University Press.

Larrivee, B. (2000). Transforming teaching practice: Becoming the critically reflective teacher. Reflective Practice, 1/3, 293-307. https://doi.org/10.1080/713693162

Loughran, J. J. (2010). What expert teachers do: Teachers' professional knowledge of classroom practice. Sydney, Australia: Allen \& Unwin, Routledge.

Loughran, J. J. \& Hamilton, M. L. (2016). Developing an understanding of teacher education. In J. J. Loughran \& M. L. Hamilton (Eds.), International handbook of teacher education (pp 3-22). Singapore: Springer. https://doi.org/10.1007/978-981-100366-0_1

Mangubhai, F., Marland, P., Dashwood, A., \& Son, J. B. (2004).Teaching a foreign language: One teacher's practical theory. Teaching and Teacher Education, 20/3, 291311.

McNamara, D. (1990). Research on teachers' thinking: Its contribution to educating student teachers to think critically. Journal of Education for Teaching, 16/2, 147-160.

Mezirow, J. (1990). How critical reflection triggers transformative learning. In J. Mezirow (Ed.), Fostering Critical Reflection in Adulthood: A Guide to Transformative and Emancipatory Learning (pp. 1-20). San Francisco, CA: Jossey-Bass Publishers.

Mullock, B. (2006). The pedagogical knowledge base of four TESOL teachers. The Modern Language Journal, 90/1, 48-66. Nias, J. (1996). Thinking about feeling: The emotions in teaching. Cambridge Journal of Education, 26/3, 293-306.

Osterman, K. F., \& Kottkamp, R. B. (2004). Reflective practice for educators: Professional development to improve student learning. Thousand Oaks, CA: Corwin Press. 
Pacheco, A. Q. (2011). Reflective teaching and its impact on foreign language teaching. Actualidades Investigativasen en Educación, 5/3, 1-19.

Park, S., \& Oliver, J. S. (2008). Revisiting the conceptualization of pedagogical content knowledge (PCK): PCK as a conceptual tool to understand teachers as professionals. Research in Science Education, 38/3, 261-284.

Patton, M. Q., (2014). Qualitative research and evaluation methods: Integrating theory and practice (Fourth Edition). Thousand Oaks, CA: Sage Publications.

Pollard, A., \& Collins, J. (2005). Reflective teaching: Evidence-informed professional practice. New York, NY: Continuum Intl Pub Group.

Reed, Y., Davis, H., \& Nyabanyaba, T. (2002). Investigating teachers' take-up of reflective practice from an in-service professional development teacher education program in South Africa. Educational Action Research, 10/2, 253-274.

Richards, J. C. (1998). Beyond training: Perspectives on language teacher education. Cambridge, UK: Cambridge University Press.

Richards, J. C., \& Lockhart, C. (1994). Reflective teaching in second language classrooms. New York: Cambridge University Press.

Richardson, V., \& Placier, A. (2001). Teacher change. In V. Richardson (Ed.), Handbook of research on teaching (4th ed., pp. 905-947). Washington, DC: American Educational Research Association.

Schön, D. A. (1983). The reflective practitioner: How professionals think in action. New York: Basic Books.

Schön, D. A. (1987). Educating the reflective practitioner: Towards a new design for teaching and learning in the professions. San Francisco: Jossey-Bass.

Shulman, L. (1987). Knowledge and teaching: Foundations of the new reform. Harvard Educational Review, 57/1, 1-22. https://doi.org/10.17763/haer.57.1.j463w79r56455411

Smyth, J. (1989). Developing and sustaining critical reflection in teacher education. Journal of Teacher Education, 40/2, 2-9. https://doi.org/10.1177/002248718904000202

Sparks-Larger, G., \& Colton, A. (1991). Synthesis of research on teachers' reflective thinking. Educational Leadership, 48/6, 37-44.

Tsui, A. B. M. (2003). Understanding expertise in teaching. Cambridge: Cambridge University Press. https://doi.org/10.1017/cbo9781139524698.011

Watzke, J. L. (2007). Foreign language pedagogical knowledge: Toward a developmental theory of beginning teacher practice. The Modern Language Journal, 91/1, 63-82.

Woods, D., \& Çakir, H. (2011). Two dimensions of teacher knowledge: The case of communicative language teaching. System, 39/3, 381-390.

Xia J. (2002). A report on investigating the College English teachers' knowledge of and beliefs in foreign language education and their roles in teaching, researching, and professional development. Foreign Language World, 91/5, 35-41. 
Yost, D. S. (2006). Reflection and self-efficacy: Enhancing the retention of qualified teachers from a teacher education perspective. Teacher Education Quarterly, 33/4, 5976.

Yost, D. S., Sentner, S. M., \& Forlenza-Bailey, A. (2000). An examination of the construct of critical reflection: Implications for teacher education programming in the 21st century. Journal of Teacher Education, 51/1, 39-49.

Zeichner, K. M., \& Liston, D. P. (2013). Reflective teaching: An introduction (2nd ed.). New York: Routledge. 